\title{
POSITIVE SOLUTIONS FOR SINGULAR NONLOCAL BOUNDARY VALUE PROBLEMS INVOLVING NONLINEAR INTEGRAL CONDITIONS
}

\author{
BAOQIAng Yan, Donal O’Regan and Ravi P. Agarwal
}

\begin{abstract}
In this paper, using the fixed point theory on a cone and Leray-Schauder fixed point theorem, we present some existence results for singular nonlocal boundary value problems involving nonlinear integral conditions. Our nonlinearity may be singular in its dependent variable and it is allowed to change sign.
\end{abstract}

Mathematics subject classification (2010): 34B10, 34B15, 34B18.

Keywords and phrases: integral boundary conditions, singularity, cone, positive solutions.

\section{REFERENCES}

[1] R.P. Agarwal And D. O'REgan, Existence theory for single and multiple solutions to singular positone boundary value problems, J. Differential Equations, 175, 2 (2001), 393-414.

[2] R.P. AgARWAL AND D. O'REGAN, A survey of recent results for initial and boundary value problems singular in the dependent variable, Original Research Article Handbook of Differential Equations: Ordinary Differential Equations, 1 (2000), 1-68.

[3] J.V. BAXLEY, A singular nonlinear boundary value problem: membrane response of a spherical cap, SIAM J. Appl. Math., 48, 3 (1988), 497-505.

[4] L.E. Bobisud, J.E. CALVERT AND W.D. RoyAlty, Some existence results for singular boundary value problems, Differential Integral Equations, 6, 3 (1993), 553-571.

[5] K. Deimling, Nonlinear functional analysis, Springer Verlag, New York, 1985.

[6] C.S. Goodrich, On a Nonlocal BVP with Nonlinear Boundary Conditions, Results. Math., 63, 3-4 (2013), 1351-1364.

[7] D. Guo And V. Lakshmikantham, Nonlinear Problems in Abstract Cones, Academic Press, 1988.

[8] G. InFANTE, Eigenvalues and positive solutions of ODEs involving integral boundary conditions, Discrete Contin. Dyn. Syst., Supplement Volume(2005), 436-442.

[9] G. InFANTE AND J.R.L. WEBB, Positive solutions of some nonlocal boundary value problems, Abstr. Appl. Anal., 2003, 18 (2003), 1047-1060.

[10] C. JI AND B. YAN, Positive solutions for second-order singular three-poin boundary-value problems with sign-changing nonlinearities, Electronic Journal of Differential Equations, 2010, 38 (2010), 1-9.

[11] D. O'REGAn, Existence theory for nonlinear ordinary differential equations, Kluwer Acad. Publ., Dordrecht, 1997.

[12] S. TAliaferro, A nonlinear singular boundary value problem, Nonlinear Analysis, 3, 6 (1979), 897-904.

[13] J. R. L. WebB And G.Infante, Positive Solutions of Nonlocal Boundary Value Problems: A Unified Approach, Journal London Mathematical Society, 74, 3(2006), 673-69.

[14] J. R. L. WebB AND G. InfAnte, Positive solutions of nonlocal boundary value problems involving integral conditions, Nonlinear Differential Equations and Applications, 15(2008), 45-67.

[15] G. C. YANG, Positive solutions of singular Dirichlet Boundary value problems with sign-changing nonlinearities, Computers and Mathematics with Applications, 51, 9-10(2006), 1463-1470. 